\title{
Effects of salbutamol on bronchoconstriction, bronchial hyperresponsiveness, and leucocyte responses induced by platelet activating factor in man
}

\author{
K FAN CHUNG, GORDON DENT, PETER J BARNES \\ From the Department of Thoracic Medicine, National Heart and Lung Institute, Brompton Hospital, London
}

ABSTRACT Platelet activating factor, a potent mediator of inflammation, causes a sustained increase $\circ$ in airway responsiveness to methacholine in man and has been implicated in asthma. The effect of the beta $_{2}$ agonist salbutamol ( $200 \mu \mathrm{g}$ by inhalation) on platelet activating factor induced bronchocon- $\mathbb{T}$ striction and airway hyperresponsiveness was studied in seven normal subjects in a double blind, 을 crossover study. Salbutamol only partially inhibited the platelet activating factor induced fall in partial flow at $30 \%$ of vital capacity $\left(\dot{\mathrm{V}} \mathrm{p}_{30}\right.$ ) (mean percentage fall 47.6 (SEM 7.9); $\mathrm{p}<0.001$ ), whereas it completely blocked a similar degree of bronchoconstriction induced by methacholine. Salbutamol did not prevent the accompanying transient flushing and chest irritation and did not affect the transient neutropenia (mean \% fall $69.5(13.6)$; $p<0.01$ ) or the rebound neutrophilia (mean \% increase $84.7(24.7) ; \mathrm{p}<0.05)$ that followed platelet activating factor. There was an increase in the airway responsiveness to methacholine following inhalation of platelet activating factor, the maximum mean change being a three fold increase in $\mathrm{PC}_{40}$ (the provocative concentration of $\frac{O}{\mathbb{D}}$ methacholine causing a $40 \%$ fall in $\left.\dot{V} p_{30}\right)$ on day $3(p<0.01)$. Salbutamol caused a significant $\frac{2}{\vec{F}}$ attenuation of this response on day $3(p<0.02)$ but had no significant effect on days 1 and 7 . Thus a $\frac{\rho}{3}$ therapeutic dose of salbutamol caused partial inhibition of platelet activating factor induced bronchoconstriction and had a minimal effect on the increased bronchial responsiveness following platelet activating factor.

\section{Introduction}

Platelet activating factor is an inflammatory mediator that could contribute to several features of asthma. It is a potent bronchoconstrictor agent, and causes a sustained increase in bronchial responsiveness to methacholine,' a feature that is characteristic of asthmatic airways. ${ }^{2}$ It is chemotactic for the eosinophil, ${ }^{34}$ a prominent cell present in the airways of those with asthma, and it is extremely potent in inducing airway microvascular leakage. ${ }^{5}$

Beta adrenergic agonists are used as bronchodilator agents in asthma and are presumed to relax airway smooth muscle directly. ${ }^{6}$ Beta agonists are also potent inhibitors of histamine release from human lung mast

Address for reprint requests: Dr K F Chung, Department of Thoracic Medicine, National Heart and Lung Institute, Brompton Hospital, London SW3 6LY.

Accepted 3 November 1988 cells, ${ }^{7}$ and in addition attenuate the in vitro release of mediators from activated neutrophils ${ }^{8}$ but not from eosinophils. ${ }^{9}$ At high concentrations they prevent the o development of microvascular leakiness induced by inflammatory mediators in animals. ${ }^{10}$ In view of the 을 potential role of inflammatory mechanisms under- $D$ lying the bronchial hyperresponsiveness of asthma, beta agonists may therefore be expected to have some $\bar{N}$ beneficial effect. They have little effect, however, on 5 the bronchial hyperresponsiveness that develops after $\tilde{O}$ allergen challenge. ${ }^{12}$

To evaluate the effect of beta agonists further we 0 have examined whether salbutamol, administered by

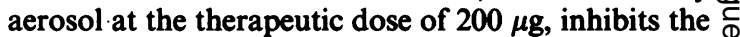
acute bronchoconstriction and bronchial hyper- $\stackrel{\mathcal{P}}{?}$ responsiveness induced by platelet activating factor in $T$ normal subjects (in whom there is no question of prior $\bar{D}$ beta agonist treatment). We have also studied its effect $\stackrel{\mathbb{D}}{\AA}$ on the transient but substantial leucopenia that occurs $\mathbb{\otimes}$ after inhalation of platelet activating factor. 


\section{Methods}

\section{SUBJECTS}

Seven normal, non-asthmatic and non-smoking adults aged 23-40 years (six male) gave informed consent to participate in the study, which was approved by the hospital ethics committee. One subject was atopic as indicated by positive skinprick test responses to several common allergens. All subjects had been free of upper respiratory tract infections for at least four weeks. The baseline forced expiratory volume in one second $\left(F^{2} V_{1}\right)$ was within $95 \%$ of the value predicted for age and height. The subjects refrained from drinking beverages containing caffeine for two hours before challenge on each day.

\section{STUDY DESIGN}

Each subject was studied during two periods separated by at least four weeks. Airway responsiveness to methacholine was measured first and one to two days later the subject inhaled platelet activating factor (PAF). Responsiveness to methacholine was measured one, three, and seven days later at the same time of day. Twenty minutes before PAF exposure each subject inhaled two puffs of salbutamol (Ventolin $200 \mu \mathrm{g}$ ) or matched placebo from a metered dose inhaler in a double blind, randomised fashion. Baseline lung function was measured every five minutes before inhalation of PAF.

\section{PAF INHALATION CHALLENGE}

PAF (Novabiochem AG, Switzerland) at a concentration of $10 \mathrm{mg} / \mathrm{ml}$, was stored in $100 \%$ ethanol at $-20^{\circ} \mathrm{C}$. On the study day a $2 \mathrm{mg} / \mathrm{ml}$ solution was prepared in $0.9 \%$ saline containing $0.03 \%$ heat treated human serum albumin. The diluent had no effect on baseline airway function. PAF aerosol was delivered from a nebuliser attached to a dosimeter (MEFAR, Brescia, Italy) driven by compressed air at a pressure of $152 \mathrm{kPa}\left(22 \mathrm{lb} / \mathrm{in}^{2}\right)$ with an output of $6 \mu \mathrm{l} / \mathrm{breath}$. For each nebulisation (which lasted for 1.0 second) the subject inhaled for three seconds from functional residual capacity to total lung capacity and held his breath for seven seconds before breathing out normally. Because of the development of rapid tachyphylaxis in the bronchoconstrictor response to PAF, we administered equal doses of PAF (two breaths, $24 \mu \mathrm{g}$ ) every 15 minutes on six occasions (total dose $144 \mu \mathrm{g}$ ). The response to PAF was measured from volume standardised partial expiratory flow-volume curves $^{13}$ with a rolling spirometer (Vitalograph, Buckingham) and a Hewlett-Packard microcomputer (Collingwood Measurements, Leicester). Measurements of $\dot{V} p_{30}$ were made one, three, five, 10 , and 15 minutes after each inhalation of PAF. Responses were expressed as the percentage fall from the $V p_{30}$ measurement made 20 minutes after inhalation of salbutamol or placebo. In five of the subjects we examined the effect of salbutamol $(200 \mu \mathrm{g})$ on the bronchoconstriction induced by methacholine.

\section{METHACHOLINE CHALLENGE}

Methacholine challenge was performed with inhalation of increasing doubling concentrations of methacholine chloride (Sigma, UK). ${ }^{1}$ The provocative concentration of methacholine needed to cause a $40 \%$ fall in baseline $\dot{\mathrm{V}}_{30}\left(\mathrm{PC}_{40}\right)$ was computed from log concentration-response curves by linear interpolation.

\section{MEASUREMENT OF CIRCULATING CELLS}

Samples of venous blood $(2 \mathrm{ml})$ were taken from an intravenous cannula inserted in a forearm vein before and five and 15 minutes after the first three inhalations of PAF for measurement of total white cell and platelet counts on a Coulter Counter 880 (Coulter Electronics, Hialeah, Florida). Differential cell counts were performed on 100 cells from blood smears stained with May-Grünwald-Giemsa by an independent observer unaware of the protocol. We also sampled blood in two subjects before and after inhalation of a bronchoconstrictor dose of methacholine.

\section{DATA ANALYSIS}

$\mathrm{PC}_{40}$ values were log transformed before analysis. All data have been reported as means and standard errors. To determine the effect of PAF on airways responsiveness a two factor analysis of variance and the Newman-Keuls multiple range test were performed..$^{14}$ To determine whether salbutamol had an effect on PAF responses a paired $t$ test was used to compare the values after salbutamol and placebo. P values less than 0.05 were considered significant.

\section{Results}

All subjects noticed facial flushing and coughing after inhaling the first dose of PAF; one subject described a raw feeling in the chest. Prior inhalation of salbutamol did not prevent these symptoms. The symptoms were considerably less after the second inhalation and were absent on subsequent inhalations.

\section{PAF INDUCED BRONCHOCONSTRICTION}

After placebo the first inhalation of PAF caused a maximal percentage fall of $\dot{\mathrm{V}} \mathrm{p}_{30}$ to 56.6 (SEM 3.3) of the post-placebo value at five minutes, with a recovery to $78.3(9 \cdot 1)$ by 15 minutes. Subsequent inhalations of PAF caused no further fall in $\dot{V} p_{30}$, and by the fifth and sixth inhalations $\hat{V}_{p_{30}}$ had gradually recovered towards baseline values (table, fig 1). Salbutamol caused a $42.1 \%(11.0 \%)$ increase in $\mathrm{V}_{30}(\mathrm{p}<0.01)$ 
Effects of placebo and salbutamol on partial flow at $30 \%$ of vital capacity $\left(V p_{30}, l / \mathrm{min}\right)$ and the subsequent changes in $V p_{30}$ after each inhalation of platelet activating factor (PAF)

\begin{tabular}{|c|c|c|c|c|c|c|c|c|}
\hline \multirow[b]{2}{*}{ Subject No } & \multirow[b]{2}{*}{ Baseline } & \multirow[b]{2}{*}{$20 \min$} & \multicolumn{6}{|c|}{$P A F$ inhalation number } \\
\hline & & & $I^{*}$ & 2 & 3 & 4 & 5 & 6 \\
\hline \multicolumn{9}{|l|}{ PLACEBO } \\
\hline $\begin{array}{l}1 \\
2 \\
3 \\
4 \\
5 \\
6 \\
7 \\
\text { Mean } \\
\text { SEM }\end{array}$ & $\begin{array}{c}130.2 \\
124.8 \\
130 \\
88.2 \\
175.1 \\
172.1 \\
126 \\
135.2 \\
12.3\end{array}$ & $\begin{array}{l}124 \\
104 \\
122.4 \\
84.7 \\
180.5 \\
182 \\
126 \\
131.9 \\
15.0\end{array}$ & $\begin{array}{r}64.7 \\
60.7 \\
60.4 \\
56.9 \\
82.0 \\
117.4 \\
74.9 \\
73.9 \\
8.6\end{array}$ & $\begin{array}{r}81.1 \\
61.2 \\
84.9 \\
75.2 \\
124.7 \\
130.8 \\
75.6 \\
90.5 \\
10.8\end{array}$ & $\begin{array}{c}74.1 \\
64.2 \\
76.8 \\
50.2 \\
123.3 \\
168 \\
93.3 \\
92.8 \\
16.5\end{array}$ & $\begin{array}{r}72.3 \\
63.4 \\
76.5 \\
92.9 \\
131.9 \\
130.7 \\
94.7 \\
94.6 \\
11.2\end{array}$ & $\begin{array}{r}104.9 \\
85.4 \\
96.2 \\
105.2 \\
163.2 \\
166.8 \\
104.8 \\
118.1 \\
13.4\end{array}$ & $\begin{array}{c}73.6 \\
112 \\
109.8 \\
78.6 \\
-\quad \\
172.5 \\
112.0 \\
109.8 \\
14.4\end{array}$ \\
\hline \multicolumn{9}{|c|}{ SALBUMATOL $(200 \mu \mathrm{g})$} \\
\hline $\begin{array}{l}1 \\
2 \\
3 \\
4 \\
5 \\
6 \\
7 \\
\text { Mean } \\
\text { SEM }\end{array}$ & $\begin{array}{l}152.1 \\
117.8 \\
125.6 \\
122.7 \\
168 \\
170.6 \\
129.6 \\
140.9 \\
9.1\end{array}$ & $\begin{array}{r}211.1 \\
131.6 \\
147.7 \\
206.4 \\
214.3 \\
246.9 \\
241.5 \\
199.9 \\
18.0\end{array}$ & $\begin{array}{l}169 \\
102 \\
134.2 \\
195.7 \\
120.7 \\
241.6 \\
209.0 \\
167.5 \\
20.8\end{array}$ & $\begin{array}{r}162.7 \\
108.8 \\
119.6 \\
210.2 \\
153.3 \\
220.9 \\
187.1 \\
166.1 \\
17.5\end{array}$ & $\begin{array}{r}167.5 \\
116.1 \\
110.7 \\
158.8 \\
170.8 \\
231.3 \\
202.8 \\
165.4 \\
17.7\end{array}$ & $\begin{array}{l}143 \cdot 5 \\
121 \\
149 \\
246.5 \\
191 \cdot 8 \\
253.9 \\
211 \cdot 1 \\
188.1 \\
21.3\end{array}$ & $\begin{array}{r}136.4 \\
110.1 \\
126.5 \\
233.7 \\
195.9 \\
219.5 \\
204.4 \\
175.2 \\
20.2\end{array}$ & $\begin{array}{r}183.9 \\
124.6 \\
127.1 \\
247.7 \\
199.5 \\
164.6 \\
186.5 \\
176.3 \\
17.5\end{array}$ \\
\hline
\end{tabular}

*Five minutes after each PAF inhalation.

and partially inhibited the bronchoconstrictor effect of PAF. The mean $\mathrm{V}_{30}$ at five minutes fell by $32 \cdot 5(12 \cdot 2)$ $1 /$ min after salbutamol compared with $58 \cdot 1(8.9) 1 /$ min after placebo $(p<0.05)$. By contrast, salbutamol completely inhibited a larger degree of bronchoconstriction induced by methacholine (maximal \% fall in $\dot{\mathrm{V}} \mathrm{p}_{30} 39.6$ (3.0) from baseline; after salbutamol the maximal \% fall in $\mathrm{V}_{30}$ was only $3.9(2.4)$ of the postsalbutamol value.
BRONCHIAL RESPONSIVENESS TO METHACHOLINE PAF inhalation resulted in a significant decrease in $\mathrm{PC}_{40}$ to methacholine by day 3 , and the effect was still present by day 7 (for placebo $p<0.01$; for salbutamol $\mathrm{p}<0.025$ : fig 2). After placebo the mean $\mathrm{PC}_{40}$ fell from $18.2 \mathrm{mg} / \mathrm{ml}(\ln$ SEM 0.285 ) to $6.2 \mathrm{mg} / \mathrm{ml}$ (ln SEM $0 \cdot 198$ ); after salbutamol it fell from $19.4 \mathrm{mg} / \mathrm{ml}$ (ln SEM 0.285) to $9.8 \mathrm{mg} / \mathrm{ml}$ ( $\ln$ SEM 0.246) on day 3 (fig 2). On day 3 the mean $P_{40}$ after salbutamol was

$$
\dot{\mathrm{V}} \mathrm{p}_{30}
$$

(\% control)

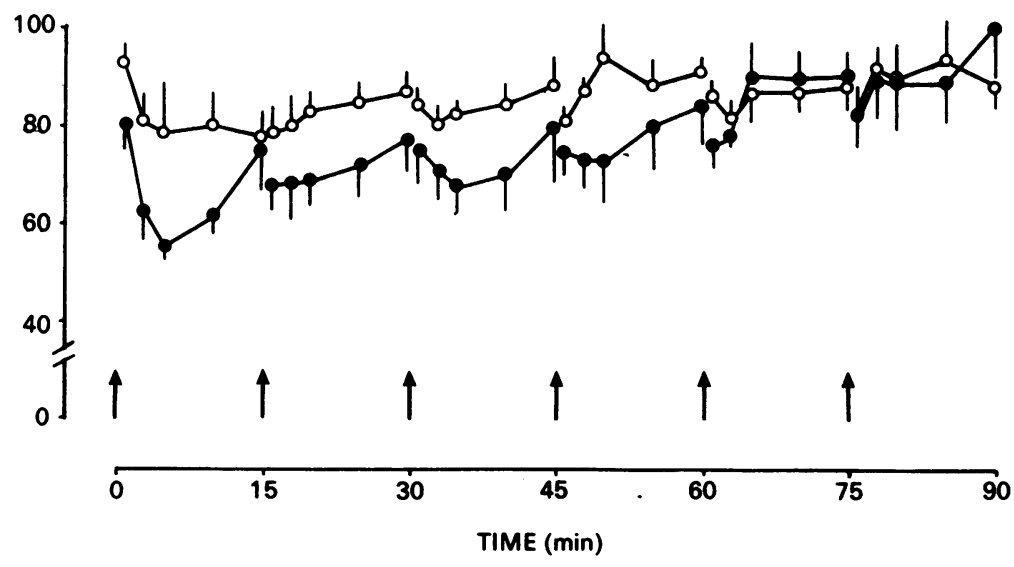

Fig 1 Effect of inhaled placebo (O) and salbutamol (O) on the partial expiratory flow at $30 \%$ vital capacity ( $\dot{V} p_{30}$, means and $S E M)$ after inhalation of platelet activating factor (PAF) (24 $\mu \mathrm{g}$ ) every 15 minutes as indicated by arrows. $\dot{V} p_{30}$ is expressed as a percentage of the value obtained 20 minutes after the inhalation of placebo or salbutamol. 


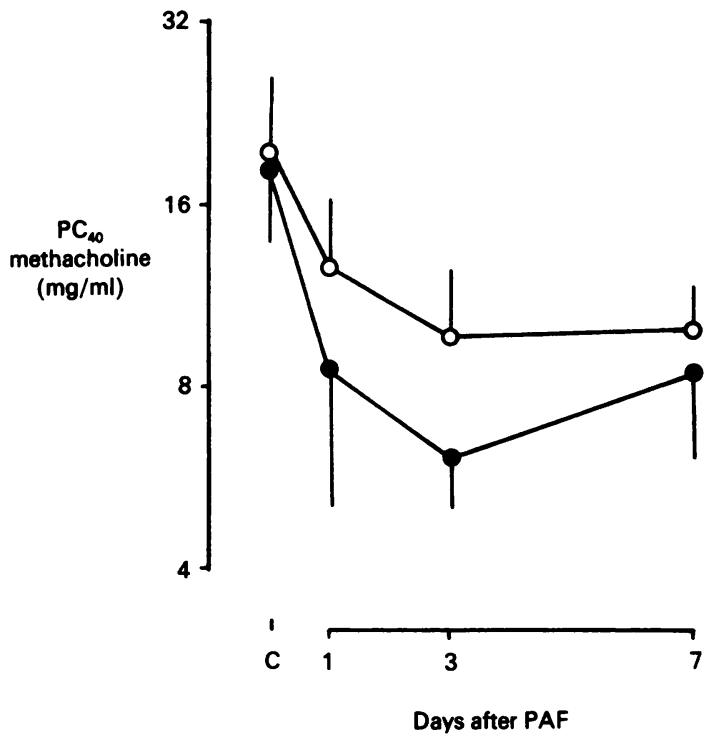

Fig 2 Effect of inhaled placebo (O) and salbutamol (O) on the change in bronchial responsiveness to methacholine induced by platelet activating factor (PAF). Bronchial responsiveness was measured as the concentration of methacholine causing a $40 \%$ fall in baseline partial expiratory flow at $30 \%$ vital capacity $\left(P_{40}\right.$ ) (geometric means and geometric $S E M)$. After placebo $P C_{40}$ was reduced maximally by day $3(p<0.01)$; after salbutamol $P C_{40}$ was also reduced by day $3(p<0.025)$, though the reduction was attenuated $(p<0.02)$.

significantly higher than the mean after placebo $(p<$ 0.02). There were no significant differences, however, on either day 1 or day 7 .

\section{EFFECT ON CIRCULATING CELLS}

There were no significant changes in the circulating platelet count after PAF inhalation (fig 3). The total white cell count fell in all subjects initially by $46.4 \%$ $(10.1 \%)$ five minutes after PAF $(p<0.02)$, but this was followed by a rebound leucocytosis, with a $52.9 \%$ $(14.7 \%)$ mean increase over the baseline values at 15 minutes $(p<0.02)$. The leucocytosis persisted and did not change further with subsequent inhalations of PAF. There was a fall in circulating neutrophils of $69.5 \%(13.7 \%)$ five minutes after placebo $(p<0.01)$, followed by an increase of $84.7 \%(24.7 \%)$ at 15 minutes (p < 0.05; fig 3). Salbutamol did not inhibit the transient neutropenia. Methacholine did not alter total white cell and neutrophil counts in two subjects, in whom $\mathrm{Vp}_{30}$ fell by $85 \cdot 6 \%$ and $70 \cdot 2 \%$.

\section{Discussion}

We have confirmed our previous observation that platelet activating factor causes immediate bronchoconstriction and a sustained increase in responsiveness to inhaled methacholine, with a maximal mean threefold decrease in mean $\mathrm{PC}_{40}$ occurring three days after inhalation. ${ }^{115}$ Salbutamol at the usual therapeutic dose only partly inhibited the bronchoconstrictor response, whereas it completely inhibited a slightly greater bronchoconstrictor response to inhaled methacholine in the same subjects. It did not prevent the systemic and local symptoms caused by PAF inhalation nor did it affect the transient neutropenia. Salbutamol had only a small inhibitory effect on the increased bronchial responsiveness to PAF seen on day 3 ; it had no effect on the increased responsiveness seen on days 1 and 7 after inhalation of platelet activating factor.

The mechanisms by which PAF induces a sustained increase in airways responsiveness remain speculative. This effect of platelet activating factor could be initiated through the induction of inflammation in the
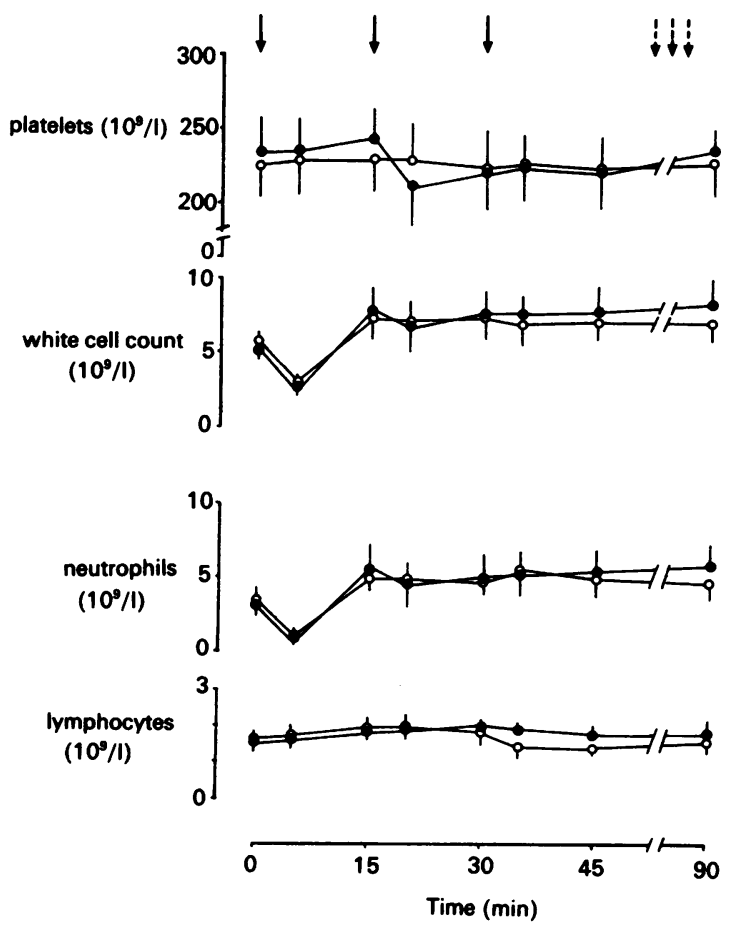

Fig 3 Effect of inhaled placebo (O) and salbutamol (O) on the change in circulating cell counts (means and SEM) after successive inhalations of platelet activating factor (PAF) as indicated by arrows. The total white count fell by five minutes $(p<0.02)$ with a rebound leucocytosis by 15 minutes $(p<0.02)$. Further inhalations of $P A F$ had no effect. The transient leucopenia was reflected by a fall in neutrophil counts $(p<0.01)$. Salbutamol had no significant effect. 
airways, perhaps through recruitment of circulating eosinophils into the airway wall. ${ }^{316}$ Beta adrenergic agonists such as salbutamol are not effective in inhibiting the release of inflammatory mediators such as superoxide anions and eosinophil peroxidase from eosinophils stimulated in vitro by opsonised zymosan. $^{9}$ Thus if the eosinophil were crucial in the development of bronchial hyperresponsiveness induced by platelet activating factor beta adrenergic agonists would have little effect on this hyperresponsiveness. The transient fall in circulating neutrophils after inhalation of platelet activating factor does not necessarily implicate the neutrophil as an important cell in PAF induced broncial hyperresponsiveness. This may have been due to temporary sequestration of these cells within the pulmonary circulation, perhaps through vessel margination. In dogs bronchial hyperresponsiveness induced by PAF is accompanied by neutrophilia in bronchoalveolar lavage fluid. ${ }^{17}$

Platelet activating factor also has potent effects on airway microvascular permeability, ${ }^{5}$ and subsequent microvascular leakage leads to plasma extravasation and oedema of the airways. Because salbutamol, with its potent effects as an airway smooth muscle relaxant, only partially protected against the acute bronchial response to platelet activating factor, possibly the residual effect on $V p_{30}$ is a reflection of oedema of the airways produced by PAF. In support of this possibility is the complete protection afforded by salbutamol against methacholine induced bronchoconstriction of the same degree as that caused by platelet activating factor in the same subjects. If part of the acute response to inhaled platelet activating factor were due to airway oedema, this might explain why there is no relation between the responsiveness to platelet activating factor and that to methacholine, ${ }^{1}$ which is presumed to be only a smooth muscle constrictor. Furthermore, asthmatic subjects do not appear to be more sensitive to platelet activating factor than normal subjects. ${ }^{18}$ This lack of hyperresponsiveness to a mediator in asthma was previously reported for leukotriene (LT) D4, ${ }^{19}$ though subsequent studies showed that asthmatic subjects are hyperresponsive to LTC4 and LTD4. ${ }^{20}{ }^{21}$ Increased airway wall thickness due to oedema has been proposed as a possible mechanism of increased bronchial responsiveness. ${ }^{22}$ Whether airways oedema could persist for as long as three days or more after a single exposure to platelet activating factor is doubtful and the possibility that airways oedema is linked to airways hyperresponsiveness remains unproved.

It is worth comparing the effects of salbutamol on the airway effects produced by platelet activating factor and by antigen because PAF has been suggested as a putative mediator in asthma. Salbutamol com- pletely inhibits the early bronchoconstrictor respons to antigen, but has no effect on the antigen induced? bronchial hyperresponsiveness seen seven hours afte? challenge. ${ }^{12}$ By contrast, salbutamol caused only par믐 tial inhibition of the bronchoconstriction induced by platelet activating factor and had a minimal effect im reducing PAF induced bronchial hyperresponsivenesङ on day 3 with no effect on the decrease in $\mathrm{PC}_{40}$ on days 1 and 7. Overall, the effect of salbutamol on hyper: responsiveness was very small, and is in accordance with the lack of inhibition by beta adrenergic agonis? drugs on allergen induced hyperresponsiveness. ${ }^{12}$

This work was supported by the Asthma Research Council and the Medical Research Council.

\section{References}

1 Cuss FM, Dixon CMS, Barnes PJ. Effects of inhaleकू platelet activating factor on pulmonary function and bronchial responsiveness in man. Lancet 1986;ii 189-92.

2 Boushey HA, Holtzman MJ, Sheller JR, Nadel JA: Bronchial hyperreactivity. Am Rev Respir Dis 1980 121:389-413.

3 Wardlaw AJ, Moqbel R, Cromwell O, Kay AB. Platelet activating factor. A potent chemotactic and chemo kinetic factor for human eosinophils. $J$ Clin Inves 1986;78:1701-6.

4 Henocq E, Vargaftig BB. Skin eosinophilia in atopiō patients. J Allergy Clin Immunol 1988;87:691-5.

5 Evans TW, Chung KF, Rogers DF, Barnes PJ. Effect of platelet-activating factor on airway vascular permeability: possible mechanisms. J Appl Physiol 1987;63 479-84.

6 Barnes PJ, Ind PW, Dollery CT. Beta adrenoceptors in asthma and their response to agonists. In: Kay $A B_{0}^{-}$ Austen KF, Lichtenstein LM, eds. Asthma: Physi ology, immunopharmacology and treatment. Londonis Academic Press, 1984: 339-58.

7 Peters SB, Schulman ES, Schleimer RP, Macglashan DW, Newball HH, Lichtenstein LM. Dispersed human lung mast cells. Pharmacologic aspects and compari- $\rightarrow$ son with human lung tissue fragments. Am Rev Respir Dis 1982;126:1034-9.

8 Wong $\mathrm{K}$, Freund $\mathrm{K}$. Inhibition of the $N$-formylmethionyl-leucyl-phenylalanine induced respiratory burst in $N$ human neutrophils by adrenergic agonists and prosta-N glandins of the E series. Can J Physiol Pharmaco ${ }_{10}^{5}$
$1981 ; 59: 915-20$.

9 Yukawa T, Chanez P, Dent G, Kroegel C, Chung KFo Barnes PJ. Bronchodilator agents do not inhibit oxygen-free radical release from guinea-pig eosinophils ${ }^{-}$ [Abstract]. Am Rev Respir Dis 1988;137:A27.

10 O'Donnell SR, Persson CGA. $\beta$-Adrenoceptor mediatedō inhibition by terbutaline of histamine effects on vas- $\mathbb{D}$ cular permeability. Br J Pharmacol 1978;62:321-4.

11 Chung KF. Role of inflammation in the hyperreactivity 
of the airways in asthma. Thorax 1986;41:657-62.

12 Cockcroft DW, Murdoch KY. Comparative effects of inhaled salbutamol, sodium cromoglycate, and beclomethasone dipropionate on allergen-induced early asthmatic responses, late asthmatic responses, and increased bronchial responsiveness to histamine. $J$ Allergy Clin Immunol 1987;79:734-40.

13 Barnes PJ, Gribbin HR, Osmanliev D, Pride NB. Partial flow-volume curves to measure bronchodilator doseresponse curves in normal man. J Appl Physiol 1981;50: 1193-7.

14 Zar JH. Biostatistical analysis. Englewood Cliffs, New Jersey: Prentice-Hall, 1974:151-5.

15 Chung KF, Minette P, McCusker M, Barnes PJ. Ketotifen inhibits the cutaneous but not the airway responses to platelet-activating factor in man. J Allergy Clin Immunol 1988;81:1192-7.

16 Lellouch-Tubiana A, Lefort J, Simon MT, Pfister A, Vargaftig BB. Eosinophil recruitment into guinea-pig lungs after PAF-Acether and allergen administration. Am Rev Respir Dis 1988;137:948-54.

17 Chung KF, Aizawa HA, Leikauf GD, Ueki IF, Evans
TW, Nadel JA. Airway hyperresponsiveness induced by platelet-activating factor: role of thromboxane-A2. $J$ Pharmacol Exp Ther 1986;236:580-4.

18 Chung KF, Dixon CMS, Barnes PJ. Platelet-activating factor (PAF) and asthmatic airways: effects of caliber, responsiveness and circulating cells [Abstract]. $\mathrm{Am} \mathrm{Rev}$ Respir Dis 1987;135:A159.

19 Griffin M, Weiss JW, Leitch AG, et al. Effect of leukotriene D4 on the airways in asthma. $N$ Engl J Med 1983;308:436-9.

20 Bisgaard H, Groth S, Madsen F. Bronchial hyperreactivity to leukotriene D4 and histamine in exogenous asthma. $\mathrm{Br}$ Med J 1985;290:468-71.

21 Adelroth E, Morris MM, Hargreave FE, O'Byrne PM. Airway responsiveness to leukotrienes $\mathrm{C} 4$ and $\mathrm{D} 4$ and to methacholine in patients with asthma and normal controls. N Engl J Med 1986;315:480-4.

22 Freedman BJ. The functional geometry of the bronchi. The relationship between changes in external diameter and calibre, and a consideration of the passive role played by the mucosa in bronchoconstriction. Bull Physiopathol Respir 1972;8:545-57. 